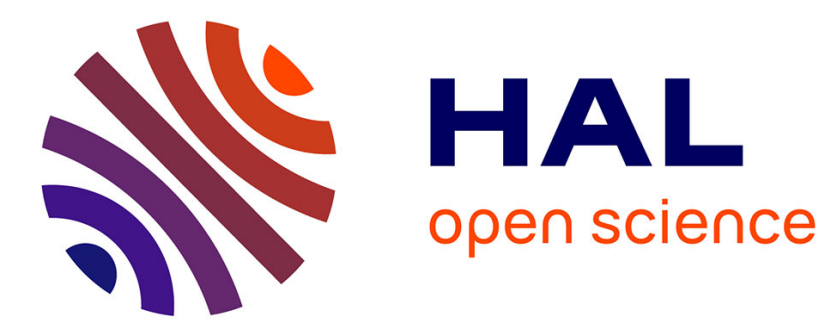

\title{
Extreme polyandry improves a honey bee colony's ability to track dynamic foraging opportunities via greater activity of inspecting bees
}

\author{
Heather Mattila, Thomas Seeley
}

\section{- To cite this version:}

Heather Mattila, Thomas Seeley. Extreme polyandry improves a honey bee colony's ability to track dynamic foraging opportunities via greater activity of inspecting bees. Apidologie, 2014, 45 (3), pp.347-363. 10.1007/s13592-013-0252-3 . hal-01234731

\section{HAL Id: hal-01234731 \\ https://hal.science/hal-01234731}

Submitted on 27 Nov 2015

HAL is a multi-disciplinary open access archive for the deposit and dissemination of scientific research documents, whether they are published or not. The documents may come from teaching and research institutions in France or abroad, or from public or private research centers.
L'archive ouverte pluridisciplinaire HAL, est destinée au dépôt et à la diffusion de documents scientifiques de niveau recherche, publiés ou non, émanant des établissements d'enseignement et de recherche français ou étrangers, des laboratoires publics ou privés. 


\title{
Extreme polyandry improves a honey bee colony's ability to track dynamic foraging opportunities via greater activity of inspecting bees
}

\author{
Heather R. Mattila ${ }^{1}$, Thomas D. SeEley ${ }^{2}$ \\ ${ }^{1}$ Department of Biological Sciences, Wellesley College, 106 Central Street, Science Center, Wellesley, MA 02481, \\ USA \\ ${ }^{2}$ Department of Neurobiology and Behavior, Cornell University, Ithaca, NY 14853, USA
}

Received 6 June 2013 - Revised 12 October 2013 - Accepted 23 October 2013

\begin{abstract}
We explored the worker-level interactions that enhance the organization of foraging in honey bee colonies with extremely polyandrous queens by determining whether a colony's patriline number affects the activity of its inspectors (foragers who visit a previously utilized food source to see if it is profitable again). We monitored the use of sucrose feeders by foragers in free-flying colonies that had either multiple patrilines or a single patriline as the feeders were sequentially stocked, emptied, and then restocked. Multiple-patriline colonies tended to have more inspectors than single-patriline colonies, their inspectors inspected their feeder at higher rates when it was empty, and then foraged at higher rates and performed more waggle runs when it was restocked, which quadrupled feeder recruitment. The patriline profile for a colony's inspectors consistently differed from that of its general population. We show clear ergonomic benefits of extreme polyandry for honey bee queens and their colonies.
\end{abstract}

extreme polyandry / division of labor / genotypic variability / waggle dance recruitment / inspector bees

\section{INTRODUCTION}

The tremendous success of the eusocial Hymenoptera is for many species tied to a complex social organization that allows behavioral and morphological specialists to respond swiftly to rapid changes in their environment (Hölldobler and Wilson 2008, p. 85-93). As social complexity increases across taxa, it brings with it a trend toward greater colony

Electronic supplementary material The online version of this article (doi:10.1007/s13592-013-0252-3) contains supplementary material, which is available to authorized users.

Corresponding author: H. Mattila, hmattila@wellesley.edu

Manuscript editor: Stan Schneider size and longevity (Bourke 1999; Jeanne 1999; Johnson and Linksvayer 2010) and a competitive superiority that fuels ecological dominance (Wilson 1990). The vast number of individuals in such insect societies requires a level of productivity that is sustained most effectively when colony members not only specialize in tasks but also share information about their colony's needs and available resources. The selective advantage of combining these two social traits is perhaps best exemplified by the emergence of their fluid interaction when colony members forage cooperatively. For species where foraging specialists recruit nest mates to food sources, the ability of colonies to extract resources from their surroundings soars. For instance, workers in a mature leafcutter colony (Atta colombica) can consume 
more plant biomass annually than a large deer in the same habitat $(>500 \mathrm{~kg}$ dry weight/colony; Herz et al. 2007) and local resource depletion by colonies of army ants is considered the primary reason for their frequent emigration to new nest sites (Franks and Fletcher 1983; Schöning et al. 2005). In honey bees, a typical colony weighing $3-5 \mathrm{~kg}$ collects enough floral resources to consume $60 \mathrm{~kg}$ of honey and $20 \mathrm{~kg}$ of pollen each year (Seeley 1985, p. 82).

An additional layer of social complexity is superimposed on social insect colonies for species whose queens mate promiscuously. Monandry and the close relatedness it creates within colonies is the ancestral state for the eusocial Hymenoptera, yet extreme polyandry by queens has evolved in 13 genera (Hughes et al. 2008). In these instances, the potential disadvantages of low relatedness within colonies and the perceived risks of overexposure inherent in this mating strategy, such as transmission of disease from drones to queens and their offspring (de Miranda and Fries 2008; da Cruz-Landim et al. 2012), costs of sperm storage (Baer et al. 2006), or queens not making it home safely (Tarpy and Page 2000; Schlüns et al. 2005), have been selectively outweighed by the extraordinary diversity of subfamilies (patrilines) that extreme polyandry generates in a colony and the functional benefits of their presence. These benefits are proving to be substantial. The probability of workers performing tasks differs across patrilines, and the presence of such genetic task specialists within multiple-patriline colonies is thought to enhance their ability to respond to environmental perturbation and disease [reviewed by Oldroyd and Fewell (2007); see also Table I and discussion below]. At the level of the colony, increasing complexity of its genetic structure is linked to greater foraging productivity and growth in the short term, and survival and reproductive success in the long term [for bees, ants, and wasps: Oldroyd et al. (1992); Cole and Wiernasz (1999); Murakami et al. (2000); Goodisman et al. (2007); Mattila and Seeley (2007); Mattila et al. (2008); Wiernasz et al. (2004, 2008)].
Of the $\sim 15,000$ known species of eusocial Hymenoptera, many species have queen mating frequencies that are greater than one, but less than $0.2 \%$ of species have queens that are highly polyandrous (i.e., $>3$ mates per queen, with many species having much higher effective mating frequencies; summarized by Hughes et al. (2008) in Table S1 and including subsequently identified taxa identified by Evison and Hughes (2011) or summarized by Leniaud et al. (2011) and Chappell et al. (2013)]. Because of the rarity of this extreme mating strategy, it is intriguing that many groups that are notable for their promiscuous queens are also wellrecognized for their impressively vigorous and expansive foraging efforts. This short list of heavy hitters includes the aforementioned army ants (Denny et al. 2004; Kronauer et al. 2004, 2006, 2007), leaf-cutter ants (Boomsma et al. 1999; Evison and Hughes 2011), and honey bees (Tarpy and Nielsen 2002; Tarpy et al. 2004). The size of these colonies, the morphological and/or behavioral flexibility of their foragers, and their ability to quickly recruit to new food sources affords them a competitive edge that can hinder other insects, including social insects, from accessing resources in their shared habitat (Goulson et al. 2002; Kaspari and O’Donnell 2003; Dohzono and Yokoyama 2010; Cerdá et al. 2013).

Across these groups, there is good evidence of a strong influence of patriline membership on the extent to which workers participate in foraging, which can be due to differences in the distribution of polymorphic worker castes across patrilines [e.g., ants: Hughes et al. (2003); Rheindt et al. (2005); Jaffé et al. (2007); Waddington et al. (2010); Evison and Hughes (2011); Huang et al. (2013), but see Wiernasz and Cole (2010)] or behavioral differences where workers are monomorphic [e.g., honey bees: summarized by Table I]. While the benefits of genetic diversity for colony-level productivity have been documented empirically across taxa, the worker-level processes that generate greater productivity in multiplepatriline colonies have been most fully explored in honey bees, where the organization of 
Table I. Studies that have reported an effect of patriline membership on the propensity of workers to perform foraging-related tasks for honey bee and ant genera with extremely polyandrous queens. The majority of citations refer to studies that compare task performance among true patrilines (i.e., shared mother, but different father). However, some citations compared task performance between genetic groups that were not true patrilines (see footnotes). For honey bees, many studies report patriline effects at insemination frequencies that are lower than those of naturally mated queens (Tarpy and Nielsen 2002; Tarpy et al. 2004).

\begin{tabular}{|c|c|c|c|}
\hline Genus & $\begin{array}{l}\text { Type of foraging- } \\
\text { related task }\end{array}$ & Source of genotypic diversity & Reference \\
\hline \multirow[t]{22}{*}{ Apis } & \multirow{2}{*}{$\begin{array}{l}\text { General foraging, } \\
\text { undefined }\end{array}$} & 19-22 patrilines per colony & Chapman et al. (2007) \\
\hline & & $14-15$ patrilines per colony & Mattila and Seeley (2010) \\
\hline & \multirow[t]{2}{*}{ Onset of foraging } & $\begin{array}{l}2 \text { "sublines" co-fostered in multiple- } \\
\text { patriline colonies }\end{array}$ & Calderone and Page (1988) \\
\hline & & 2 patrilines per colony & Kolmes et al. (1989) \\
\hline & \multirow[t]{2}{*}{ Scouting } & 3 patrilines per colony & Dreller (1998) \\
\hline & & $14-16$ patrilines per colony & Mattila and Seeley (2011) \\
\hline & Inspecting & $18-20$ patrilines per colony & This study \\
\hline & \multirow[t]{7}{*}{ Type of forage } & $\begin{array}{l}2 \text { "sublines" co-fostered in multiple- } \\
\text { patriline colonies }^{\mathrm{a}}\end{array}$ & Calderone and Page (1988) \\
\hline & & 3 "subgroups" & Calderone et al. (1989) \\
\hline & & 3 patrilines per colony & Robinson and Page (1989) \\
\hline & & 2 patrilines per colony & Oldroyd (1991) \\
\hline & & 2 patrilines per colony & Oldroyd et al. (1992) \\
\hline & & 8 "subgroups"c & Dreller et al. (1995) \\
\hline & & 16 patrilines in 1 colony & Kryger et al. (2000) \\
\hline & Time of day & 11-12 patrilines & Kraus et al. (2011) \\
\hline & $\begin{array}{l}\text { Preferred foraging } \\
\text { distance }\end{array}$ & 2 patrilines per colony & Oldroyd et al. (1993) \\
\hline & \multirow[t]{4}{*}{ Waggle dancing } & 2 patrilines per colony & Oldroyd et al. (1991) \\
\hline & & 17 patrilines in 1 colony & Arnold et al. (2002) \\
\hline & & $\begin{array}{l}3 \text { unrelated patrilines compared across } \\
\text { foster colonies }{ }^{\mathrm{a}, \mathrm{d}}\end{array}$ & Duong et al. (2008) \\
\hline & & $14-15$ patrilines per colony & Mattila and Seeley (2010) \\
\hline & Tremble dancing & 17 patrilines in 1 colony & Arnold et al. (2002) \\
\hline & $\begin{array}{l}\text { Shaking/vibrational } \\
\text { signal }\end{array}$ & $\begin{array}{l}3 \text { unrelated patrilines compared across } \\
\text { foster colonies }{ }^{\text {a, d }}\end{array}$ & Duong et al. (2008) \\
\hline \multirow[t]{2}{*}{ Acromyrmex } & $\begin{array}{l}\text { General foraging, } \\
\text { undefined }\end{array}$ & 5-7 patrilines per colony & Waddington et al. (2010) \\
\hline & Foraging efficiency & $\begin{array}{l}3-5 \text { patrilines per colony considered in } \\
\text { analysis }\end{array}$ & Constant et al. (2012) \\
\hline Cataglyphis & $\begin{array}{l}\text { General foraging, } \\
\text { undefined }\end{array}$ & $5-6$ patrilines per colony & Eyer et al. (2012) \\
\hline
\end{tabular}

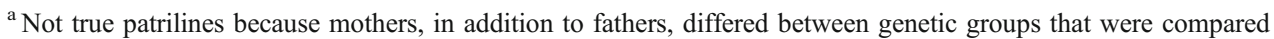

${ }^{\mathrm{b}}$ Effect not found consistently found across replicates

${ }^{\mathrm{c}}$ Genetic subgroups may contain more than one patriline

${ }^{\mathrm{d}}$ Genetic groups that were compared were not co-fostered
} 
cooperative foraging relies on an assemblage of foraging workers who occupy one of several behavioral states at any given moment. According to the scout-recruit model of Biesmeijer and de Vries (2001), an active forager may utilize a food source because she is a scout who independently discovered it through exploration, or because she is a new recruit or an experienced forager who obtained information about it from a waggle dance, or because she is an inspector with previous knowledge of the food source who learned of its renewed profitability by checking on it herself. Although workers can shift between these behavioral states and, thus, modes of resource discovery and exploitation (Seeley 1983; Biesmeijer and Seeley 2005; Johnson and Frost 2012), a worker's genetic makeup influences her participation in this process (Table I). Field studies are revealing in increments how genetic diversity enhances foraging effort for each behavioral category under which a honey bee forager can operate (see Section 4 for more details). However, gaps in our understanding remain.

One major chasm to be bridged is exploring how the activity of "inspector" bees contributes to more productive foraging in colonies with multiple patrilines. The role of inspectors is an important one for organizing a colony's foraging effort-the majority (i.e., $67 \%$ ) of foragers who exploit a previously known food source do so because they inspected that source themselves (possibly returning to it several times while it yields no reward), not because they were reactivated by recruitment signals (Biesmeijer and Seeley 2005). The activity of inspectors permits the foraging collective to sensitively track short-term changes in resource availability (Granovskiy et al. 2012). In this study, we compared differences in foraging activity when discovery and recruitment depended on the performance of inspectors for colonies that either had multiple patrilines because queens were inseminated with sperm from many males (the derived state for Apis) or only a single patriline because queens were inseminated with the sperm from one male (the ancestral state for the eusocial Hymenoptera). To do this, we trained individually identifiable workers from both types of colonies to use food sources under free-flying conditions, then we monitored the extent to which workers inspected their colony's food source after it was emptied, and we subsequently tracked their rediscovery and ability to recruit to it when it was restocked. This approach allowed us to evaluate whether genetic structure affected the speed and strength of a colony's response to changes in food availability, as well as the ways in which the activity of individual workers shaped this response. We also determined whether a bee's likelihood of inspecting was influenced by her patriline membership and the relative activity of inspector-rich patrilines. Our study is the first to explore how foragers who function in the behavioral state of "inspector" are affected by high levels of genetic diversity resulting from promiscuous mating by honey bee queens.

\section{MATERIALS AND METHODS}

\subsection{Creating single-patriline and multiple- patriline colonies}

To understand how intracolonial genetic diversity influences the activity of inspector bees, we created single-patriline and multiple-patriline colonies, produced by queens who were inseminated by either a single drone per queen or $18-20$ drones per queen, according to the methods of Mattila and Seeley (2011). Briefly, each queen received $1 \mu \mathrm{L}$ of semen from either one drone or a set of drones that was unique to her; drones were selected at random from a pool of 1,000 drones that were derived from 20 unrelated colonies (each colony contributed 50 drones to the pool). All inseminations were performed by a queen breeder (Glenn Apiaries, Fallbrook, CA, USA) who reared supersister queens $(r=0.75)$ of Carniolan descent for this study. The insemination status of each queen was coded by the queen breeder, who labeled queens as belonging to either group A or B only; codes were revealed after all data were collected. 
Sixteen singly inseminated queens and 12 multiply inseminated queens were introduced into queenless colonies at Cornell's Liddell Field Station (Ithaca, NY, USA) in late April 2008. Colonies were inspected weekly thereafter to confirm that queens were laying well; poorly laying queens or colonies showing signs of disease were removed from the study. Eight weeks later, when the host colonies' worker populations had been completely replaced by the progeny of the inseminated queens, three colonies from each treatment group were selected at random from 15 single-patriline colonies and 10 multiplepatriline colonies (i.e., those colonies that remained in the study because they exhibited signs of normal health and function). Colonies from each treatment group were randomly paired as replicates for testing at the Cranberry Lake Biological Station (CLBS; Cranberry Lake, NY, USA; $\left.44^{\circ} 09^{\prime} \mathrm{N}, 74^{\circ} 48^{\prime} \mathrm{W}\right)$.

\subsection{Evaluating the activity of inspectors}

The activity of inspector bees was compared between single-patriline and multiple-patriline colonies by working with pairs of colonies at the CLBS. The advantage of the CLBS's location is that there is relatively little natural forage available to support honey bees, which standardized foraging conditions across replicates (as much as possible in a natural setting). Also, we could train free-flying foragers to utilize artificial sucrose feeders without interference from locally established colonies in the area. Each pair of colonies was studied over a 4-day period, one pair at a time, from late June to the end of July, 2008. Before relocating a pair of colonies to the CLBS, we first transferred each colony's queen, $\sim 4,000$ workers, and two frames of brood and food to a two-frame observation hive (there was no more than a $5 \%$ difference between paired colonies in the area of comb that was covered by brood or food). Once in the observation hives, colonies were moved from Liddell and installed side-by-side in a building at the CLBS.

Once installed, workers could freely exit the observation hives through tubes that led outside through the west wall of the building. The observation hive entrances were $10 \mathrm{~m}$ apart, similarly shaded by trees, and had yellow or blue cards $(22 \times 28 \mathrm{~cm})$ fixed under them to aid foragers' orientation to their new hive entrances. The next day, we trained workers in both colonies to visit feeders that were located $300 \mathrm{~m}$ from the observation hives, but in opposite directions from one another. The colony at on the north end of the building always used the feeder that was $300 \mathrm{~m}$ northeast of the hives and the colony at the south end always used the feeder that was the same distance from the hives in the southwest direction (positions were alternated between treatments across the replicates). The next day, we trained workers to use their feeder. To do this, one of the colonies was screened up in the early morning and foragers in the other colony were permitted to discover and utilize their feeder as we gradually moved it over several hours from the colony's entrance to its final location, following Seeley (1995, p. 78). The feeder was stocked with $0.5 \mathrm{M}$ anise-scented sucrose solution to get foragers to return to it, but with minimal recruitment so that the feeder did not become overcrowded. Once the feeder was in its final location, we paint marked the abdomen of $\sim 30$ foragers as they visited the feeder. We then emptied that feeder and screened up the hive after the majority of marked foragers had returned to it; stragglers were captured at the entrance and reintroduced into the hive through a stoppered hole above the second frame. Once the first hive was screened, we unscreened the second hive and trained that colony's workers to visit the second feeder using the same techniques. All feeder-visiting foragers were marked with the paint color that matched their hive's color-coded entrance, permitting us thereafter to immediately identify and remove any individuals who discovered the other colony's feeder (this occurred only once during the study). After foragers had been marked at each feeder, both colonies were allowed to forage freely over the remainder of the day.

Over four subsequent days, we followed a similar daily routine: in the morning, we filled the feeders with sucrose solution and gave the foragers who visited them individually identifiable paint marks and, in the afternoon, we evaluated how frequently these marked foragers inspected the feeders when they were emptied and how efficiently these foragers discovered and recruited to the feeders when they were eventually refilled. To get all of this done in 
1 day, we closely followed a schedule and attempted to collect data only if good weather was predicted all day. At 6 A.M., we screened up both hives to prevent foragers from leaving before testing started. At 8 A.M., we unscreened one colony's hive, stocked that colony's feeder with $0.5 \mathrm{M}$ anise-scented sucrose solution, and put a droplet of the solution in the hive's entrance (the hive that was unscreened first was alternated between treatments over 4 days of testing). Between 8-10 A.M., we marked each forager who showed up at the feeder with two paint colors on her thorax, giving each forager an individually identifiable mark. If an unmarked forager showed up during training, she was first painted on her abdomen with her hive's paint color and then marked on her thorax on a subsequent visit. Between 10-11 A.M., we emptied the feeder, allowed all marked foragers to return to their hive, screened up the hive, and then captured all stragglers that were trying to get in and returned them to the hive through the hole above the second frame. Between 11 A.M. and 1 P.M., we unscreened the second hive, put a droplet of solution in its entrance, filled the second colony's feeder, and paint marked all workers who visited it. The individually identifiable foragers from a colony who were marked at their feeder before 1 P.M. are hereafter referred to as that colony's "focal foragers". At 1 P.M., we emptied both feeders, unscreened the first hive, and let both colonies fly freely for the remainder of the day. For the first $2 \mathrm{~h}$, no data were recorded from the colonies or at the feeders. At 3 P.M., observers were stationed at the feeders and they recorded at 1-min intervals over the next hour the identity of each marked focal forager who visited a feeder. At the end of this "inspection hour" (4 P.M.), we refilled the feeder with $1.5 \mathrm{M}$ anise-scented sucrose solution (a concentration that is more likely to elicit recruitment dancing by foragers) and again recorded at 1-min intervals the identity of each focal forager who returned to the feeder. We also recorded the number of unmarked foragers who showed up at each feeder; these foragers were presumably recruited to their feeder by dances performed by the paint-marked focal foragers. These waggle dances were captured by video cameras that recorded each colony's dance floor (i.e., the area of comb immediately adjacent to the hive's entrance); an observer at the hives pointed out the identity of all dancing focal foragers for the recordings. We restricted waggle dancing to the focal foragers by capturing all unmarked recruits at the feeder and holding them in a screened cage until the "reemployment and recruitment hour" was over. For these latter $2 \mathrm{~h}$, we determined total number of inspections, foraging trips, and recruitment signals produced by focal foragers over 4 days of testing, their per capita activity rates as they inspected, exploited, and recruited to the feeder, and the proportion and total number of focal foragers that performed these activities. At 5 P.M., we stopped recording data, emptied both feeders, and collected as many focal foragers as possible for genotyping (see below). We also released the caged recruits, many of whom we assume were marked as focal foragers the next day.

\subsection{Identifying the patriline membership of inspectors}

The genetic structure of each multiple-patriline colony's worker population was compared to that of its inspector and focal forager subpopulations (these latter two subpopulations were also compared). The genetic structure of each colony's population was determined from samples of 150 workers collected in the early morning from multiple comb locations after the last day that a colony was tested (before foraging commenced, so all workers were at home). All worker samples were stored in alcohol until they were processed. We collected worker samples from both colonies in a pair, but genotyped workers from the multiple-patriline colonies only (once the insemination status of queens was revealed). Following the methods of Mattila and Seeley (2010), each worker was assigned to a patriline by matching her set of microsatellite markers to the markers of each inseminating drone (drone bodies were kept for this purpose). Seven highly variable microsatellite markers [A79, A7, Ap256, A113, Ap226, Ap033, and Ap068; described by Solignac et al. (2003)] unambiguously resolved the paternity of each worker. Workers who were in colonies but were not the queens' genetic offspring (identified by mismatches to the microsatellite profiles of a colony's queen and the inseminating drones) were excluded from the 
analysis. In total, we compared for each multiplepatriline colony the genetic structure of the inspector, focal forager, and general colony populations to determine whether the numbers of foragers and inspectors in each patriline were similar to those expected based on the structure of the general worker populations.

\subsection{Statistical analysis}

Inspecting, foraging, and recruiting activity of focal foragers (and inspectors only) and the arrival of recruits at feeders were compared between multiple-patriline and single-patriline colonies using two-tailed, paired $t$ tests. Either 4-day totals or daily means (averaged over 4 days) were calculated per colony, as indicated. Per capita rates of activity were determined for foragers in each colony and these values were used to calculate colony means for comparison. Proportional data were first arcsine transformed prior to analysis to improve their normality. Means are provided with standard error of the mean (s.e.m.). Because only a small number of foragers acted as inspectors, expected frequencies per patriline of inspectors were often too low for ChiSquare tests to provide accurate estimations of $P$ values. Thus, we used Monte Carlo estimates $(1,000,000$ samples per estimation) to generate exact $P$ values to compare the genetic structure of each multiple-patriline colony's inspector, focal forager, and general colony populations. Where significant differences were found, we identified patrilines that were good or poor sources of inspectors within each colony [i.e., there was at least a $50 \%$ increase in the number of workers who were inspectors in a patriline relative to the expected number based on the colony's genetic structure, according to the approach of Mattila and Seeley (2010)]. All statistical tests were performed using SAS ver. 9.3 (SAS Institute, Inc., Cary, NC, USA).

\section{RESULTS}

Over 4 days of testing per replicate, a mean total of $168 \pm 4$ workers (range, 163-177 workers) versus $116 \pm 30$ workers (range, 57147 workers) were identified as focal foragers (i.e., workers who learned to exploit their colony's feeder) per multiple-patriline and single-patriline colony, respectively. While these means are not significantly different (paired $t$ test: $t=1.8, P=0.21, d f=2$ ), fewer focal foragers were identified in single-patriline colonies. Although colonies had similar foraging opportunities and were of similar size (both total colony and focal forager populations), there were marked differences between singlepatriline and multiple-patriline colonies in the activity of inspectors when feeders were empty and in the foraging and recruitment activity of foragers when feeders were restocked. A summary of these differences is provided in Figure 1.

\subsection{Inspecting activity of focal foragers}

During the "inspection hour" over 4 days of testing per colony, the average total number of inspections of the empty feeder by focal foragers was three times greater for multiplepatriline colonies compared to single-patriline colonies (Figure 2a, paired $t$ test, $t=4.9, P=$ $0.03, d f=2)$. Greater frequency of feeder inspections in multiple-patriline colonies was generated primarily by significantly higher per capita rates of inspection for focal foragers who returned to the empty feeder (Figure $2 b$, paired $t$ test, $t=4.7, P=0.04, d f=2)$. There was also a non-significant trend toward having a higher proportion (and thus a higher number) of a colony's focal foragers inspect the empty feeder when colonies had multiple patrilines versus only a single patriline (Figure 2c, paired $t$ test, $t=2.1, P=0.17, d f=2$; Figure $2 \mathrm{~d}$, paired $t$ test, $t=2.6, P=0.12, d f=2$ ).

\subsection{Resumption of foraging by focal foragers}

After the empty feeders were restocked with sucrose solution at the end of the inspection hour, focal foragers in multiple-patriline colonies made a total of five times more trips to their feeder over 4 days of testing compared to foragers in single-patriline colonies (Figure 3a, paired $t$ test: $t=25.8, P=0.002, d f=2)$. This 
---- Single-patriline colonies

- Multiple-patriline colonies$$
\text { 高 }
$$

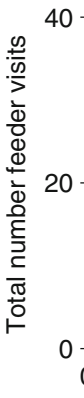

$\square$ Single-patriline colonies

- Multiple-patriline colonies

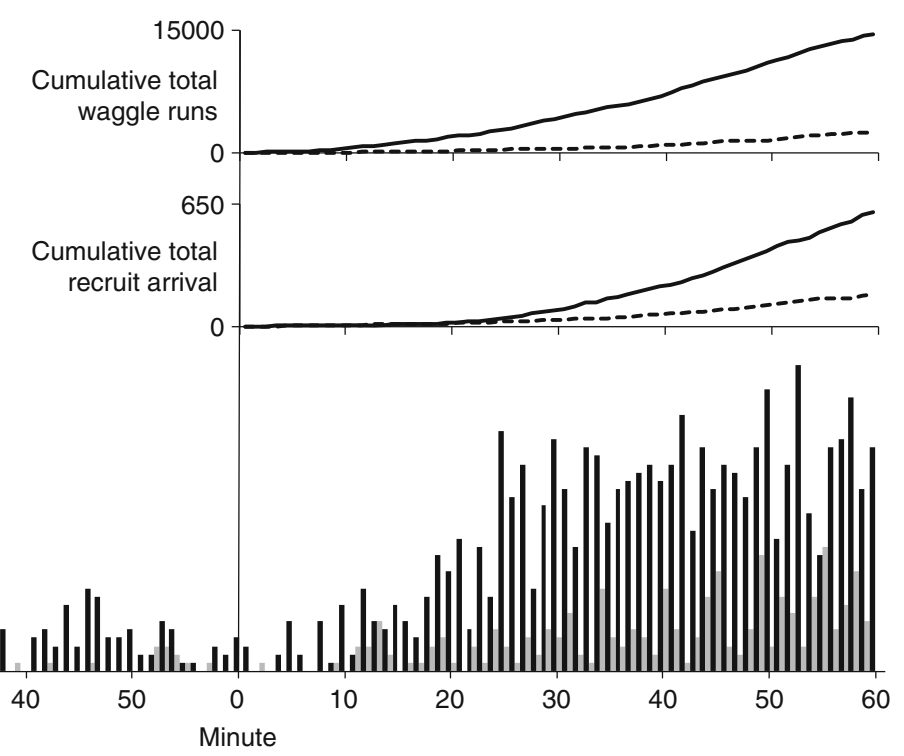

REEMPLOYMENT AND RECRUITMENT HOUR

Figure 1. Summary of foraging activity for three pairs of multiple-patriline and single-patriline colonies as they exploited feeders that were emptied and then subsequently restocked daily over 12 days of testing (4 days of testing per pair). The total number of visits to the feeders by focal foragers over the 60 -min period when they were either empty (the "inspection hour") or restocked (the "reemployment and recruitment" hour) was estimated by minute for each colony and then summed across colonies within the same treatment (i.e., summary data for the 12 days that the three pairs were tested are provided). Cumulative total number of waggle runs performed by focal foragers and total number of unmarked recruits arriving at feeders were also determined for the latter hour, with waggle run or recruit numbers estimated by minute for each colony and then summed within treatment group.

greater activity at feeders used by multiplepatriline colonies was not fuelled by a strong difference in the reemployed foragers' per capita rates of visitation (although the difference was close to the level of significance: Figure $3 b$, paired $t$ test, $t=3.7, P=0.06, d f=2$ ), but rather by a large difference in the mean proportions and absolute numbers of focal foragers who became reemployed (Figure $3 \mathrm{c}$, paired $t$ test, $t=$ 5.5, $P=0.03, d f=2$; Figure $3 \mathrm{~d}$, paired $t$ test, $t=$ 25.8, $P=0.002, d f=2$ ). While there was no difference in per capita rates of feeder visitation for reemployed focal foragers in general (Figure 3b), per capita rates of visitation for inspectors only (excluding non-inspecting focal foragers) were significantly greater in multiple-patriline compared to single-patriline colonies (mean $5 \pm 0.5$ versus $2 \pm 1.0$ feeder visits per hour, respectively; paired $t$ test, $t=$ 4.4, $P=0.04, d f=2$ ).

\subsection{Recruitment by focal foragers}

Focal foragers in multiple-patriline colonies produced over five times more waggle runs during the 4 days of testing than focal foragers in single-patriline colonies (Figure $4 \mathrm{a}$, paired $t$ test, $t=5.4, P=0.03, d f=2$ ). Mean dance rates per dancer did not differ between colony types (Figure 4b, paired $t$ test, $t=1.2, P=0.34, d f=2$ ), but both the mean proportion and the total number of focal foragers who danced were greater in multiple patriline colonies (Figure 4c, paired $t$ test, $t=8.7, P=0.01, d f=2$; Figure $4 \mathrm{~d}$, paired $t$ test, $t=9.5, P=0.01, d f=2)$. These differences in recruitment signaling resulted in 

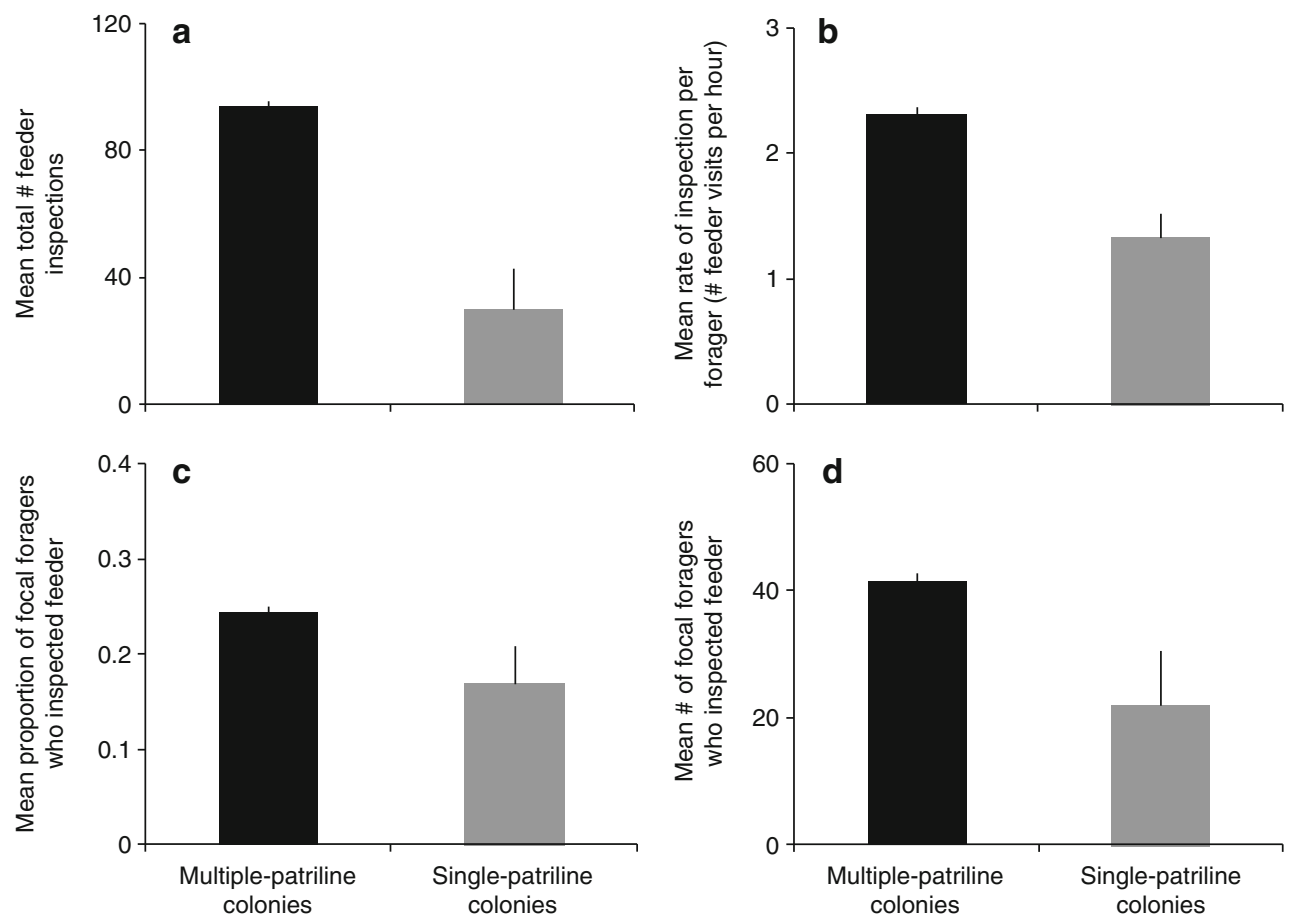

Figure 2. Mean activity levels during the "inspection hour" (+s.e.m.), when inspections of empty feeders by focal foragers in multiple-patriline and single-patriline colonies were monitored after foragers had used it earlier in the day. a Mean total feeder inspections per colony was estimated by summing the number of visits made to each colony's feeder over four "inspection hours" (4 days of testing). b Per capita rate of inspection was estimated for each focal forager who inspected the feeder. c Mean proportion and $\mathbf{d}$ mean total number per colony of all focal foragers who inspected the feeder during the "inspection hour" (over 4 days of testing).

3.6-fold more unmarked recruits arriving at the multiple-patriline colonies' feeder compared to the single-patriline colonies' feeder (mean 202 \pm 32 versus $56 \pm 21$ recruits per hour, respectively; paired $t$ test, $t=12.5, P=0.006, d f=2$ ).

Differences in recruitment were caused in part by how long it took for the restocked feeders to be reported for the first time in colonies during the "reemployment and recruitment hour." Focal foragers from multiplepatriline colonies tended to arrive sooner and dance earlier in the hour compared to foragers from single-patriline colonies (first arrival time: mean $4 \pm 0.4$ versus $25 \pm 6$ min post-restocking, respectively; paired $t$ test, $t=2.4, P=0.14, d f=2$; time of first dance: mean $15 \pm 4$ versus $35 \pm$ $8 \mathrm{~min}$ into hour, respectively; paired $t$ test, $t=$ 4.4, $P=0.04, d f=2)$. The strength of these differences are underestimated because minimum values of $60 \mathrm{~min}$ were used for calculations of single-patriline colony means for the 3 days when none of the focal foragers visited the restocked feeder and for the 5 days when none of the foragers danced for it (out of the total of 12 days that the colony pairs were monitored). Focal foragers from single-patriline colonies who inspected their feeder when it was empty often did not come back during the hour that feeders were restocked or they did not dance and therefore contributed little to nothing toward their colony's recruitment effort. For example, inspectors from two of the colonies never danced and only three inspectors in the remaining colony danced (a total of 96 waggle runs). In contrast, many more inspectors performed dances in multiple-patriline colonies 

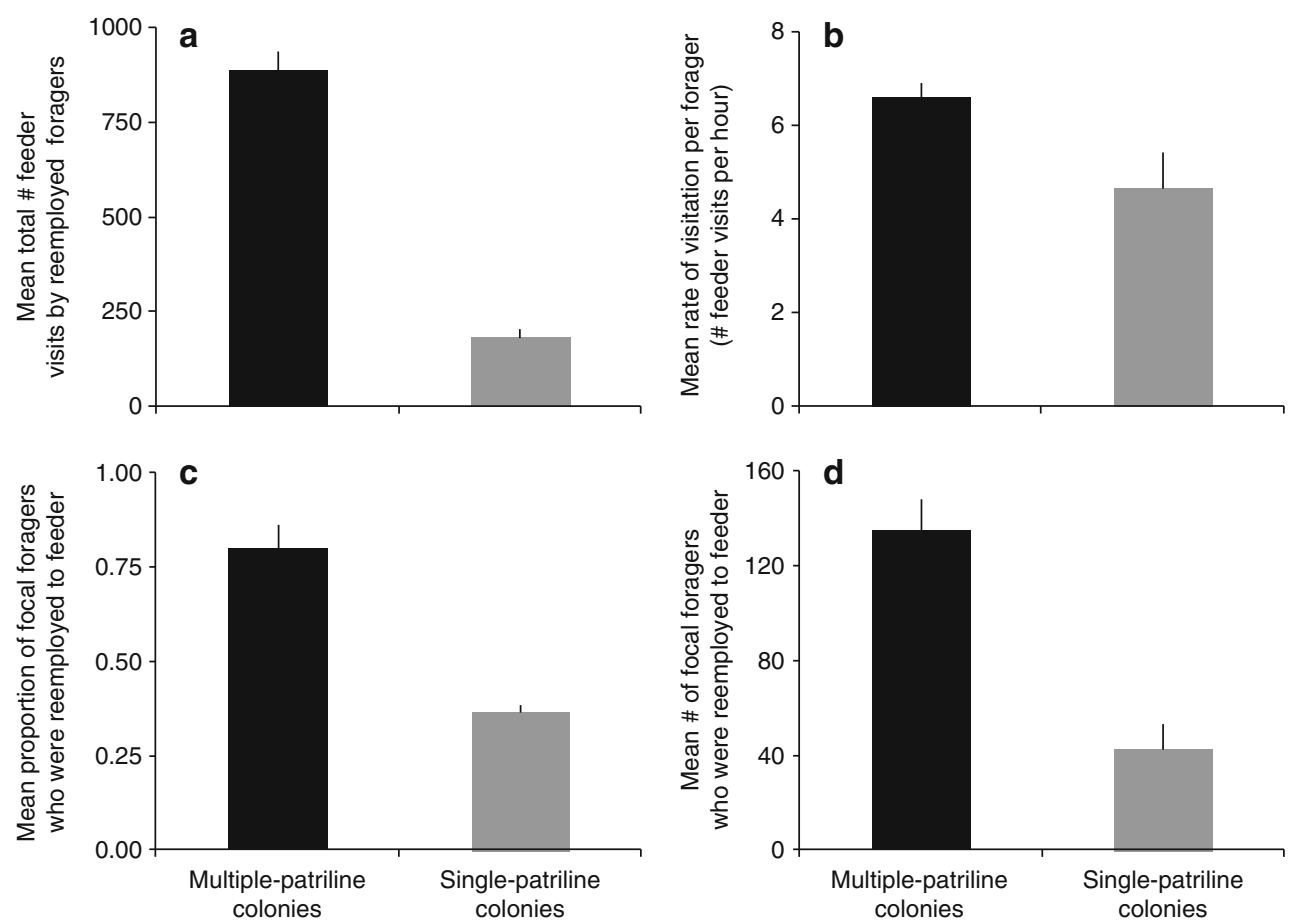

Figure 3. Mean activity levels during the "reemployment and recruitment hour" (+s.e.m.), when visitation at previously empty feeders by focal foragers in multiple-patriline and single-patriline colonies was monitored after feeders were restocked for $1 \mathrm{~h}$ per day. a Mean total feeder visits per colony was estimated by summing the number of visits made by a colony's focal foragers over four days of testing. b Per capita rate of feeder visitation was estimated for each reemployed focal forager. $\mathbf{c}$ Mean proportion and $\mathbf{d}$ mean total number per colony of all focal foragers who visited the feeder during the "reemployment and recruitment hour" (over 4 days of testing).

(17-25 dancing inspectors per colony performed a mean total of $1,085 \pm 180$ waggle runs per colony; difference in number of dancing inspectors: paired $t$ test, $t=12.4, P=0.006, d f=2$; difference in total waggle runs: paired $t$ test, $t=$ 5.0, $P=0.03, d f=2)$.

\subsection{Patriline membership of inspectors}

A total of 39-44 inspectors were identified in each multiple-patriline colony, 20-37 of which were captured for genotyping. The genetic structure of each multiple-patriline colony's inspector subpopulation was significantly different from the genetic structure of its general colony population for all three colonies and significantly different from the structure of its forager population for two of the three colonies (see Table SI for $P$ values). A small number of patrilines (one to three per multiple-patriline colony) was the source of approximately one third (31-38\%) of all inspectors in each colony (Figs. S1-S3, part a). Inspectors from this small number of patrilines performed a substantial percentage (between 20 and $37 \%$ ) of all inspecting visits to the empty feeders across the 4 days that each multiple-patriline colony was tested (Figs. S1-S3, parts b).

\section{DISCUSSION}

We show unequivocally that a swift response to dynamic shifts in resource availability was generated in multiple-patriline colonies by 

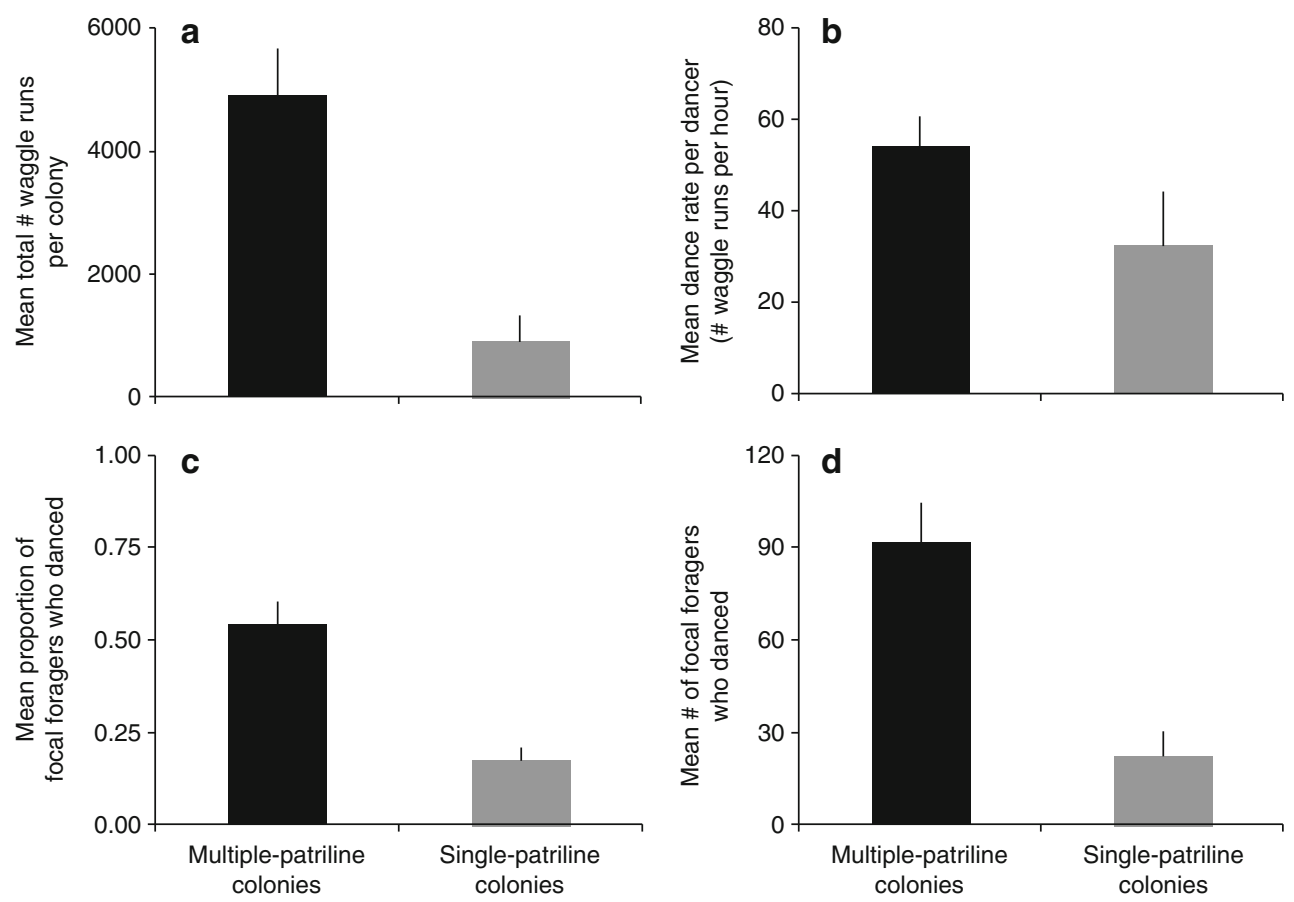

Figure 4. Mean recruitment by focal foragers in multiple-patriline and single-patriline colonies during the "reemployment and recruitment hour" (+s.e.m.), after previously empty feeders were restocked for $1 \mathrm{~h}$ per day. a Mean total waggle runs per colony was estimated by summing the number of runs performed by a colony's focal foragers over 4 days of testing. b Per capita rate of waggle dancing was determined for each focal forager who danced. $\mathbf{c}$ Mean proportion and $\mathbf{d}$ mean total number per colony of all focal foragers who danced during the "reemployment and recruitment hour" (over 4 days of testing).

increases in the activity of inspector bees, those unemployed, experienced foragers who visit previously utilized food sources to determine whether they can be exploited once more (Biesmeijer and de Vries 2001). Queens inseminated by many males (18-20 males per queen, representing the derived state for Apis) produced colonies that responded with greater rapidity and numerical strength to a renewed food source than queens that were inseminated by only a single male (the ancestral state that characterizes most eusocial hymenopteran species). Our design allowed us to compare between colony types their foragers' tendency to inspect a newly emptied feeder, the time it took for them to discover their feeder was restocked, and then their subsequent rate of exploitation and recruitment to it (with waggle dances), and the success of that recruitment effort. At all phases of this process, an increase in a colony's genotypic complexity improved its ability to sensitively track short-term changes in resource status, with greater activity at one step cascading into boosted activity at the next. On average and over the course of 4 days of testing, the foraging collective in a multiple-patriline colony inspected its feeder a total of three times more often compared to that in a single-patriline colony. More frequent feeder inspections preceded five times more trips to the feeder by foragers once they learned that it had been restocked with high-quality food. After focal foragers resumed exploiting their feeder, they produced a total of five times more waggle runs in multiple-patriline compared to singlepatriline colonies, which brought almost four times the number of new foragers (recruits) to the feeder. These differences were observed 
even though colonies in each treatment group had similar population sizes and their workers had equal opportunity to exploit the feeders (i.e., they were similarly profitable, available simultaneously, and located in the same environment).

Differences in performance at the colony level were generated by the activity of individuals in three ways. Firstly, greater numbers of workers were inclined to forage if colonies had multiple patrilines. More workers tended to inspect the feeder once it was emptied, more foragers resumed exploiting it (either via a successful inspection or by reactivation through the dances of others) when it was refilled, and more of these foragers danced (Figures 2, 3, and 4, parts d). This abundance of reemployed foragers resulted in a relatively large wave of new recruits at the multiple-patriline colonies' feeder, presumably because they sought it after more focal foragers danced to advertise it. Another way that foraging activity was enhanced in multiple-patriline colonies was through individual inspectors inspecting the feeder more frequently than their counterparts in single-patriline colonies (Figure 2b). Finally, foragers in multiple-patriline colonies tended to discover and report restocking of the feeder faster than foragers in single-patriline colonies. Thus, there were not only more individuals involved in tracking, exploiting, and recruiting to their feeder but also the individuals who functioned as inspectors performed inspections at higher per capita rates, resulting in faster discovery and reporting of its profitability.

Increased foraging activity with increased intracolony genetic diversity has been examined before at the colony level in honey bees (Mattila and Seeley 2007, 2011; Mattila et al. 2008) and in harvester ants (Wiernasz et al. 2008). However, only in honey bees have detailed behavioral studies been made to determine how individuals contribute to this phenomenon (Mattila and Seeley 2010). This work found that both the probability of taking up a task and the rate of task execution were boosted for workers in multiple-patriline colonies. Our results here confirm our previous findings and extend them into the functionally important subcategory of inspector specialists working in free-flying colonies. However, we did not find that both probability of task performance and rate of performance were consistently enhanced in our inspecting/reemployment/recruitment system. At times per capita rates of activity were greater for workers in multiple-patriline colonies compared to workers in single-patriline colonies (i.e., inspecting rates) and other times they were not (i.e., foraging and dancing rates). Interestingly, whenever per capita rates of activity did not increase in multiple-patriline colonies, the proportion of workers taking up the task increased instead. Although limited, the available evidence suggests that either mechanism operating on its own can produce a similar outcome of increased foraging productivity in a genetically diverse colony.

Because the primary driver behind the more robust response of multiple-patriline colonies to shifts in foraging opportunities is often a greater number of workers getting involved in foraging, the effects of a presence in colonies of patrilines of genetic task specialists is particularly salient. Our study, the first to look for a link between genotype and inspecting, found that the likelihood of a worker behaving as an inspector was influenced by the patriline to which she belonged (in all colonies that were studied). Approximately one third of inspectors in a colony came from a limited number (i.e., one to three) of its many patrilines, and these inspector-rich patrilines were often not the same patrilines that produced the bulk of the focal forager population (which, in addition to inspectors, is made up of scouts and foragers who use social information to find food sources). Inspectors are key to a colony's ability to sensitively track shifts in resource availability (Granovskiy et al. 2012), probably because inspecting is the most common way foragers become reemployed after an interruption, such as a rain shower, nightfall, or temporary exhaustion of a food source (Biesmeijer and Seeley 2005). Thus, the introduction into multiple-patriline colonies of inspector-rich patrilines by polyandrous queens helps to 
generate greater numbers of inspectors in those colonies and a greater show of force at a previously exploited food source when enterprising inspectors inform experienced foragers and novice recruits about its renewed status.

It has been hypothesized that selection has favored polyandry because division of labor is made more efficient when genetic task specialists, who vary in their response thresholds and likelihoods of performing tasks, are inserted into multiple-patriline colonies (Robinson and Page 1989; Oldroyd and Fewell 2007). The occurrence of genetic specialists in colonies is well supported empirically. In Table I, we summarize for species that have polyandrous queens the numerous studies that report a genotypic bias for executing tasks related to foraging. This growing body of evidence provides convincing, although indirect, support for the hypothesis that genetic task specialization boosts colony performance (note, however, that support for genetically based behavioral biases in ants is far less developed). However, 25 years after differences between a colony's genetic lines in tendencies to specialize in foraging tasks were first documented (Calderone and Page 1988), empirical studies that explore how genetic specialists improve division of foraging labor remain scarce (but see Jones et al. 2004; Mattila and Seeley 2010). To date, models have been the primary means by which researchers have explored how interacting patrilines with genetic task specializations can make colonies more resilient and productive in dynamic foraging environments (Waibel et al. 2006; Gove et al. 2009; Tarapore et al. 2010).

With our colleagues, we have approached this challenge by attempting to tease apart the contribution that workers in different behavioral categories make to the organization of a genetically diverse colony's foraging effort-a comprehensive understanding of this process is emerging from this work. In colonies with polyandrous queens, scouting specialists return to colonies at faster rates and report newly discovered food sources with longer lasting dances, thereby increasing their colony's foraging opportunities more effectively relative to colonies with monandrous queens (Mattila and Seeley 2011). In this study, inspecting specialists in multiple-patriline colonies hastened resumption of foraging at a previously exploited, but temporarily unproductive, food source by checking it with greater frequency, and then exploiting and recruiting to it more heavily when it provided food once again. In general, if a colony is genotypically diverse, then foragers of all stripes (including those who rely on waggle dances to learn about the profitability of a food source) tend to visit a food source in greater numbers and often at faster rates (this study; Mattila and Seeley 2010), producing upon return to their colonies more chemical signals that spur forager reactivation (Gilley et al. 2012; Carr-Markell et al. 2013) and more waggle dances (this study; Mattila et al. 2008; Mattila and Seeley 2010, 2011). Moreover, the dances produced in genotypically diverse colonies are better attended by dance followers (Girard et al. 2011) and result in a greater number of recruits arriving at the food source (this study). These interactions, which are powered by the interplay between the responsiveness of genetic specialists to foraging-related stimuli (Table I) and the allocation of foragers to high-quality food sources through intensified use of recruitment signals (Seeley and Visscher 1988), fuel a honey bee colony's competitive ability to discover, exploit, and mass recruit to patchy and ephemeral food sources.

The observation that species with polyandrous queens tend to have larger colonies than species with monandrous queens (Cole 1983) could be explained if the ergonomic benefits of extreme polyandry are better realized in large colonies (Crozier and Page 1985), where division of labor tends to be more complex or efficient (Wilson 1983; Jeanne 1986, 1999; Hölldobler and Wilson 2008, p. 86; Johnson and Linksvayer 2010; Holbrook et al. 2011). Within species, an increase in patriline number is linked to faster growth, larger colony size, and higher survivorship (Cole and Wiernasz 1999; Murakami et al. 2000; Mattila and Seeley 2007), and ultimately greater reproductive potential, either because colonies reach reproduc- 
tive maturity sooner (Cole and Wiernasz 1999) or because they produce more reproductive individuals (Goodisman et al. 2007; Mattila and Seeley 2007). However, one challenge large colonies face is a need to gather more food over greater area to support their population (Beekman et al. 2004). When honey bee colonies differ in size only, this cost is offset by a combination of more individuals seeking food, greater efficiency per foraging trip, and faster discovery and recruitment to rich food sources through communication (Eckert et al. 1994; Pacala et al. 1996; Donaldson-Matasci et al. 2013). We expect that the massive parallel-search and informationgathering power that emerges naturally in larger colonies (Donaldson-Matasci et al. 2013) is probably enhanced in genetically diverse colonies (relative to colonies that lack such diversity) by a tendency for proportionally more workers to forage, the presence of genetic task specialists, and enhanced communication (see above). Therefore, the challenges that are inherent in being a large colony should also be overcome by the genetic and behavioral complexities that cooccur with it in species where queens mate multiply.

In summary, our work is a strong demonstration that extreme polyandry enhances division of labor in honey bee colonies, in this case by generating a behavioral caste of "inspector" specialists, many of whom come from a small number of a colony's patrilines. More inspectors inspect formerly profitable food sources in multiple-patriline colonies compared to colonies with only a single patriline, and they do so at higher rates. Because of their vigilance and a greater propensity to dance when a food source again becomes profitable, inspectors in multiple-patriline colonies initiate a flurry of activity at a renewed food source by reactivated foragers who had exploited it previously and by recruits who are unfamiliar with it. Thus, a genetically diverse colony is better able to quickly and sensitively distribute its large pool of potential foraging effort in a shifting foraging environment, which explains in part why such colonies are more likely to thrive over the long term (Mattila and Seeley 2007). This work reveals some of the worker-level interactions that have selected for the evolution of multiple mating in a small number of highly successful lineages of bees, ants, and wasps.

\section{ACKNOWLEDGMENTS}

We are grateful to M. Girard and P. Date for enthusiastically assisting with all field work. E. Hunter and M. Girard helped to complete video analysis and genotyping. We also thank the faculty and students at the Cranberry Lake Biological Station for facilitating our work there. This study was supported by a Knafel Endowed Chair in the Natural Sciences (H.R.M.) and a Cooperative State Research, Education, and Extension Service National Research Initiative grant (2007-35302-18174) (T.D.S.).

Une forte polyandrie améliore la capacité d'une colonie d'abeilles à découvrir les opportunités d'approvisionnement dynamique grâce à l'activité plus importante des butineuses contrôlant les sources de nourriture

polyandrie / division du travail / variabilité génotypique / danse frétillante / recrutement / butineuse

Extreme Polyandrie verbessert die Fähigkeit von Honigbienen dynamisch sich ändernde Futterquellen mittels grösserer Aktivität von Suchbienen zu verfolgen und zu finden

extreme Polyandry / Arbeitsteilung / Genotypvariabilität / Schwänzeltanz / Rekrutierung / Suchbienen

\section{REFERENCES}

Arnold, G., Quenet, B., Papin, C., Masson, C., Kirchner, W.H. (2002) Intra-colonial variability in the dance communication in honeybees (Apis mellifera). Ethology 108, 751-761

Baer, B., Armitage, S.A.O., Boomsma, J.J. (2006) Sperm storage induces an immunity cost in ants. Nature 441, 872-875

Beekman, M., Sumpter, D.J.T., Seraphides, N., Ratnieks, F.L.W. (2004) Comparing foraging behaviour of small and large honey-bee colonies by decoding waggle dances made by foragers. Funct. Ecol. 18, 829-835 
Biesmeijer, J.C., de Vries, H. (2001) Exploration and exploitation of food sources by social insect colonies: a revision of the scout-recruit concept. Behav. Ecol. Sociobiol. 49, 89-99

Biesmeijer, J.C., Seeley, T.D. (2005) The use of waggle dance information by honey bees throughout their foraging careers. Behav. Ecol. Sociobiol. 59, 133142

Boomsma, J.J., Fjerdingstad, E.J., Frydenberg, J. (1999) Multiple paternity, relatedness and genetic diversity in Acromyrmex leaf-cutter ants. Proc. R. Soc. Lond. B Biol. Sci. 266, 249-254

Bourke, A.F.G. (1999) Colony size, social complexity and reproductive conflict in social insects. J. Evol. Biol. 12, 245-257

Calderone, N.W., Page Jr., R.E. (1988) Genotypic variability in age polyethism and task specialization in the honey bee, Apis mellifera (Hymentoptera, Apidae). Behav. Ecol. Sociobiol. 22, 17-25

Calderone, N.W., Robinson, G.E., Page, R.E. (1989) Genetic structure and division of labor in honeybee societies. Experientia 45, 765-767

Carr-Markell, M.K., McDonald, K.M., Mattila, H.R. (2013) Intracolonial genetic diversity increases chemical recruitment signaling by waggle dancing honey bees, Apis mellifera. Insect. Soc. doi: 10.1007/s00040-013-0315-5

Cerdá, X., Arnan, X., Retana, J. (2013) Is competition a significant hallmark of ant (Hymenoptera: Formicidae) ecology? Myrmecol. News 18, 131147

Chapman, N.C., Oldroyd, B.P., Hughes, W.O.H. (2007) Differential responses of honeybee (Apis mellifera) patrilines to changes in stimuli for the generalist tasks of nursing and foraging. Behav. Ecol. Sociobiol. 61, 1185-1194

Chappell, P., Roberts, K., Baer, B., Hughes, W.O.H. (2013) Mating systems and population genetic structure of the bulldog ant Myrmecia pavida (Hymenoptera: Formicidae). Myrmecol. News 18, 25-32

Cole, B.J. (1983) Multiple mating and the evolution of social behavior in the Hymenoptera. Behav. Ecol. Sociobiol. 12, 191-201

Cole, B.J., Wiernasz, D.C. (1999) The selective advantage of low relatedness. Science 285, 891-893

Constant, N., Santorelli, L.A., Lopes, J.F.S., Hughes, W.O.H. (2012) The effects of genotype, caste, and age on foraging performance in leaf-cutting ants. Behav. Ecol. 23, 1284-1288

Crozier, R.H., Page, R.E. (1985) On being the right size: male contributions and multiple mating in social Hymenoptera. Behav. Ecol. Sociobiol. 18, 105-115

da Cruz-Landim, C., Roat, T.C., Fernadez, F.C. (2012) Virus present in the reproductive tract of asymptomatic drones of honey bee (Apis mellifera L.), and possible infection of queen during mating. Microsc. Res. Tech. 75, 986-990 de Miranda, J.R., Fries, I. (2008) Venereal and vertical transmission of deformed wing virus in honeybees (Apis mellifera L.). J. Invert. Pathol. 98, 184-189

Denny, A.J., Franks, N.R., Powell, S., Edwards, K.J. (2004) Exceptionally high levels of multiple mating in an army ant. Naturwissenschaften 91, 396-399

Dohzono, I., Yokoyama, J. (2010) Impacts of alien bees on native plant-pollinator relationships: a review with special emphasis on plant reproduction. Appl. Entomol. Zool. 45, 37-47

Donaldson-Matasci, C., DeGrandi-Hoffman, G., Dornhaus, A. (2013) Bigger is better: honeybee colonies as distributed information-gathering systems. Anim. Behav. 85, 585-592

Dreller, C. (1998) Division of labor between scouts and recruits: genetic influences and mechanisms. Behav. Ecol. Sociobiol. 43, 191-196

Dreller, C., Fondrk, M.K., Page Jr., R.E. (1995) Genetic variability affects the behavior of foragers in a feral honeybee colony. Naturwissenschaften 82, 243-245

Duong, N., Schneider, S.S. (2008) Intra-patriline variability in the performance of the vibration signal and waggle dance in the honey bee, Apis mellifera. Ethology 114, 646-655

Eckert, C.D., Winston, M.L., Ydenberg, R.C. (1994) The relationship between population size, amount of brood, and individual foraging behavior in the honey bee, Apis mellifera L. Oecologia 97, 248255

Evison, S.E.F., Hughes, W.O.H. (2011) Genetic caste polymorphism and the evolution of polyandry in Atta leaf-cutting ants. Naturwissenschaften 98, 643649

Eyer, P.A., Freyer, J., Aron, S. (2012) Genetic polyethism in the polyandrous desert ant Cataglyphis cursor. Behav. Ecol. 24, 144-151

Franks, N.R., Fletcher, C.R. (1983) Spatial patterns in army ant foraging and migration: Eciton burchelli on Barro Colorado Island, Panama. Behav. Ecol. Sociobiol. 12, 261-270

Gilley, D.C., Kuzora, J.M., Thom, C. (2012) Hydrocarbons emitted by waggle-dancing honey bees stimulate colony foraging activity by causing experienced foragers to exploit known food sources. Apidologie 43, 85-94

Girard, M.B., Mattila, H.R., Seeley, T.D. (2011) Recruitment-dance signals draw larger audiences when honey bee colonies have multiple patrilines. Insect. Soc. 58, 77-86

Goodisman, M.A.D., Kovacs, J.L., Hoffman, E.A. (2007) The significance of multiple mating in the social wasp, Vespula maculifrons. Evolution 61, 2260-2267

Goulson, D., Stout, J.C., Kells, A.R. (2002) Do exotic bumblebees and honeybees compete with native flower-visiting insects in Tasmania? J. Insect Conserv. 6, 179-189 
Gove, R., Hayworth, M., Chhetri, M., Rueppell, O. (2009) Division of labour and social insect colony performance in relation to task and mating number under two alternative response threshold models. Insect. Soc. 56, 319-331

Granovskiy, B., Latty, T., Duncan, M., Sumpter, D.J., Beekman, M. (2012) How dancing honey bees keep track of changes: the role of inspector bees. Behav. Ecol. Sociobiol. 23, 588-596

Herz, H., Beyschlag, W., Hölldobler, B. (2007) Herbivory rate of leaf-cutting ants in a tropical moist forest in Panama at the population and ecosystem scales. Biotropica 39, 482-488

Holbrook, C.T., Barden, P.M., Fewell, J.H. (2011) Division of labor increases with colony size in the harvester ant Pogonomyrmex californicus. Behav. Ecol. 22, 960-966

Hölldobler, B., Wilson, E.O. (2008) The superorganism: the beauty, elegance, and strangeness of insect societies. W.W. Norton, New York

Huang, M.H., Wheeler, D.E., Fjerdingstad, E.J. (2013) Mating system evolution and worker caste diversity in Pheidole ants. Mol. Ecol. 22, 1998-2010

Hughes, W.O.H., Sumner, S., Van Borm, S., Boomsma, J.J. (2003) Worker caste polymorphism has a genetic basis in Acromyrmex leaf-cutting ants. Proc. Natl. Acad. Sci. U. S. A. 100, 9394-9397

Hughes, W.O.H., Oldroyd, B.P., Beekman, M., Ratnieks, F.L.W. (2008) Ancestral monogamy shows kin selection is key to the evolution of eusociality. Science 320, 1213-1216

Jaffé, R., Kronauer, D.J.C., Kraus, F.B., Boomsma, J.J., Moritz, R.F.A. (2007) Worker caste determination in the army ant Eciton burchelli. Biol. Lett. 3, 513-516

Jeanne, R.L. (1986) The organization of work in Polybia occidentalis: costs and benefits of specialization in a social wasp. Behav. Ecol. Sociobiol. 19, 333-341

Jeanne, R.L. (1999) Group size, productivity, and information flow in social wasps. In: Detrain, C., Deneubourg, J.L., Pasteels, J.M. (eds.) Information processing in social insects, pp. 3-30. Birkhäuser, Berlin

Johnson, B.R., Frost, E. (2012) Individual-level patterns of division of labor in honeybees highlight flexibility in colony-level developmental mechanisms. Behav. Ecol. Sociobiol. 66, 923-930

Johnson, B.R., Linksvayer, T.A. (2010) Deconstructing the superorganism: social physiology, groundplans, and sociogenomics. Q. Rev. Biol. 85, 57-79

Jones, J.C., Myerscough, M.R., Graham, S., Oldroyd, B.P. (2004) Honey bee nest thermoregulation: diversity promotes stability. Science 305, 402-404

Kaspari, M., O’Donnell, S. (2003) High rates of army ant raids in the Neotropics and implications for ant colony and community structure. Evol. Ecol. Res. 5, 933-939

Kolmes, S.A., Winston, M.L., Fergusson, L.A. (1989) The division of labor among worker honey bees
(Hymentoptera: Apidae): the effects of multiple patrilines. J. Kansas Entomol. Soc. 62, 80-95

Kraus, B.F., Gerecke, E., Moritz, R.F.A. (2011) Shift work has a genetic basis in honeybee pollen foragers (Apis mellifera L.). Behav. Genet. 41, 323-328

Kronauer, D.J.C., Schöning, C., Pedersen, J.S., Boomsma, J.J., Gadau, J. (2004) Extreme queenmating frequency and colony fission in African army ants. Mol. Ecol. 13, 2381-2388

Kronauer, D.J.C., Schöning, C., Boomsma, J.J. (2006) Male parentage in army ants. Mol. Ecol. 15, 11471151

Kronauer, D.J.C., Johnson, R.A., Boomsma, J.J. (2007) The evolution of multiple mating in army ants. Evolution 61, 413-422

Kryger, P., Kryger, U., Moritz, R.F.A. (2000) Genotypical variability for the tasks of watercollecting and scenting in a honey bee colony. Ethology 106, 769-779

Leniaud, L., Heftez, A., Grumiau, L., Aron, S. (2011) Multiple mating and supercoloniality in Cataglyphis desert ants. Biol. J. Linn. Soc. 104, 866-876

Mattila, H.R., Seeley, T.D. (2007) Genetic diversity in honey bee colonies enhances productivity and fitness. Science 317, 362-364

Mattila, H.R., Seeley, T.D. (2010) Promiscuous honeybee queens generate colonies with a critical minority of waggle-dancing foragers. Behav. Ecol. Sociobiol. 64, 875-889

Mattila, H.R., Seeley, T.D. (2011) Does a polyandrous honeybee queen improve through patriline diversity the activity of her colony's scouting foragers? Behav. Ecol. Sociobiol. 65, 799-811

Mattila, H.R., Burke, K., Seeley, T.D. (2008) Genetic diversity within honey bee colonies increase signal production by waggle-dancing foragers. Proc. R. Soc. Lond. B Biol. Sci. 275, 809-816

Murakami, T., Higashi, S., Windsor, D. (2000) Mating frequency, colony size, polyethism and sex ratio in fungus-growing ants (Attini). Behav. Ecol. Sociobiol. 48, 276-284

Oldroyd, B.P. (1991) Honey bees dance with their supersisters. Anim. Behav. 42, 121-129

Oldroyd, B.P., Fewell, J.H. (2007) Genetic diversity promotes homeostasis in insect colonies. Trends Ecol. Evol. 22, 408-413

Oldroyd, B.P., Rinderer, T.E., Buco, S.M. (1991) Intracolonial variance in honey bee foraging behavior: the effects of sucrose concentration. J. Apic. Res. 30, 137-145

Oldroyd, B.P., Rinderer, T.E., Harbo, J.R., Buco, S.M. (1992) Effects of intracolonial genetic diversity on honey bee (Hymenoptera: Apidae) colony performance. Ann. Entomol. Soc. Am. 85, 335-343

Oldroyd, B.P., Rinderer, T.E., Buco, S.M., Beaman, L.D. (1993) Genetic variance in honey bees for preferred foraging distance. Anim. Behav. 45, 323-332 
Pacala, S.W., Gordon, D.M., Godfray, H.C.J. (1996) Effects of social group size on information transfer and task allocation. Evol. Ecol. 10, 127-165

Rheindt, F.E., Strehl, C.P., Gadau, J. (2005) A genetic component in the determination of worker polymorphism in the Florida harvester ant Pogonomyrmex badius. Insect. Soc. 52, 163-168

Robinson, G.E., Page, R.E. (1989) Genetic determination of nectar foraging, pollen foraging, and nest-site scouting in honey bee colonies. Behav. Ecol. Sociobiol. 24, 317-323

Schlüns, H., Moritz, R.F.A., Neumann, P., Kryger, P., Koeniger, G. (2005) Multiple nuptial flights, sperm transfer and the evolution of extreme polyandry in honeybee queens. Anim. Behav. 70, 125-131

Schöning, C., Washington, M.N., Franks, N.R. (2005) Temporal and spatial patterns in the emigrations of the army ant Dorylus (Anomma) molestus in the montane forest of Mt Kenya. Ecol. Entomol. 30, $532-540$

Seeley, T.D. (1983) Division of labor between scouts and recruits in honeybee foraging. Behav. Ecol. Sociobiol. 12, 253-259

Seeley, T.D. (1985) Honeybee ecology. Princeton University Press, Princeton

Seeley, T.D. (1995) The wisdom of the hive. Harvard University Press, Cambridge

Seeley, T.D., Visscher, P.K. (1988) Assessing the benefits of cooperation in honeybee foraging: search costs, forage quality, and competitive ability. Behav. Ecol. Sociobiol. 22, 229-237

Solignac, M., Vautrin, D., Loiseau, A., Mougel, F., Baudry, E., Estoup, A., Garnery, L., Haberl, M., Cornuet, J.M. (2003) Five hundred and fifty microsatellite markers for the study of the honeybee (Apis mellifera L.) genome. Mol. Ecol. Notes 3, 307-311

Tarapore, D., Floreano, D., Keller, L. (2010) Task dependent influence of genetic architecture and mating frequency on division of labour in social insect colonies. Behav. Ecol. Sociobiol. 64, 675-684

Tarpy, D.R., Nielsen, D.I. (2002) Sampling error, effective paternity, and estimating the genetic structure of honey bee colonies (Hymenoptera: Apidae). Ann. Entomol. Soc. Am. 95, 513-528

Tarpy, D.R., Page Jr., R.E. (2000) No behavioral control over mating frequency in queen honey bees (Apis mellifera L.). Am. Nat. 155, 820-827

Tarpy, D.R., Nielsen, R., Nielsen, D.I. (2004) A scientific note on the revised estimates of effective paternity in Apis. Insect. Soc. 51, 203-204

Waddington, S.J., Santorelli, L.A., Ryan, F.R., Hughes, W.O.H. (2010) Genetic polyethism in leaf-cutting ants. Behav. Ecol. 21, 1165-1169

Waibel, M., Floreano, D., Magnenat, S., Keller, L. (2006) Division of labour and colony efficiency in social insects: effects of interactions between genetic architecture, colony kin structure and rate of perturbation. Proc. Roy. Soc. Lond. B Biol. Sci. 273, 1815-1823

Wiernasz, D.C., Cole, B.J. (2010) Patriline shifting leads to apparent genetic caste determination in harvester ants. Proc. Natl. Acad. Sci. U. S. A. 107, 1295812962

Wiernasz, D.C., Perroni, C.L., Cole, B.J. (2004) Polyandry and fitness in the western harvester ant, Pogonomyrmex occidentalis. Mol. Ecol. 13, 1601-1606

Wiernasz, D.C., Hines, J., Parker, D.G., Cole, B.J. (2008) Mating for variety increases foraging activity in the harvester ant, Pogonomyrmex occidentalis. Mol. Ecol. 17, 1137-1144

Wilson, E.O. (1983) Caste and division of labor in leafcutter ants (Hymenoptera: Formicidae: Atta) IV. Colony ontogeny of $A$. cephalotes. Behav. Ecol. Sociobiol. 14, 55-60

Wilson, E.O. (1990) Success and dominance in ecosystems: the case of the social insects. Ecology Institute, Oldendorf/Luhe 